\title{
DESEMPENHO DA FILTRAÇÃO LENTA EM AREIA SUBMETIDA A CARGAS DE PICO DE OOCISTOS DE CRYPTOSPORIDIUM SP, BACTÉRIAS E SÓLIDOS: UMA AVALIAÇÃO EM INSTALAÇÃO PILOTO
}

\author{
Performance of Slow SAND FILTRATION SubMitTED to PEAK LOADS OF \\ CRYPTOSPORIDIUM SP OOCYSTS, BACTERIA AND SOLID: AN EVALUATION \\ IN PILOT SCALE
}

\begin{abstract}
LÉO HELLER
Engenheiro Civil. Mestre em Engenharia Sanitária. Doutor em Epidemiologia. Professor do Departamento de Engenharia Sanitária e Ambiental - UFMG

Maria BerenICE CARDoso Martins VIEIRA

Bióloga com Bacharelado em Microbiologia. Mestre em Microbiologia. Doutora em Ciência Animal. Pesquisadora III - FUNED

\section{LUDMILA LADEIRA ALVES DE BRITO}

Bióloga. Mestre em Saneamento, Meio Ambiente e Recursos Hídricos. Bióloga do IBAMA

\author{
Daniella Pedrosa SaLVAdor \\ Bióloga. Bolsista da FAPEMIG
}

Recebido:19/01/05 Aceito: 04/11/05
\end{abstract}

\section{RESUMO}

Um tema chave no monitoramento dos sistemas de abastecimento de águas é a variação temporal e espacial nas concentraçôes de patogênicos, conduzindo programas de monitoramento baseados em amostras pontuais geralmente a subestimarem o risco de infecção. Em vista disto, o artigo apresenta pesquisa desenvolvida para verificar o comportamento da filtração lenta em areia, perante um aumento súbito na concentração de oocistos de Cryptosporidium e na turbidez da água, desenvolvida em unidades piloto. Os pilotos foram operados em condiçóes estacionárias seguidas por um aumento na concentração dos oocistos de Cryptosporidium parvum e, após $48 \mathrm{~h}$, com a mesma concentração de oocistos, por um aumento nos níveis de turbidez. Os testes revelaram, para os oocistos, que, enquanto na condição estacionária os efluentes apresentaram concentraçōes medianas iguais a zero, nas duas condiçôes transientes os efluentes já apresentaram oocistos, contudo a diferença não apresentou significância estatística. Apesar das condiçōes transientes, foi observada elevada remoção percentual média de oocistos de Cryptosporidium sp (99,988-99,998\%).

PALAVRAS-CHAVE: Cryptosporidium, filtração lenta, cargas de pico, turbidez, surto.

\section{INTRODUÇÃO}

Nos EUA, Cryptosporidium parvum tem atraído considerável atenção devido aos surtos de criptosporidiose atribuídos aos suprimentos de água contaminados

\section{ABSTRACT}

Temporal and space variation in the concentrations of pathogens is a key theme in the monitoring of drinking-water systems, resulting in underestimation of the infection risk in those monitoring programs based on punctual samples. Regarding this issue, the paper presents research carried out in pilot plant, aiming to verify the performance of the slow sand filtration, in a sudden increase in the Cryptosporidium oocysts concentration and in water turbidity. The pilot plant was operated in stationary conditions followed by the increase in the Cryptosporidium parvum oocysts concentration and, after $48 \mathrm{~h}$, with the same oocysts concentration, by the increase in the turbidity level. The tests revealed, for the oocysts, that, while in the stationary condition the effluent presented null concentrations medians, in the two transient conditions the effluent presented oocysts, however this difference did not accuse statistical significance. Despite the transient conditions, high average removal of Cryptosporidium sp oocysts $(99,988-99,998 \%)$ was observed.

KEYWORDS: Cryptosporidium, slow sand filtration, peak load, turbidity, outbreak.

com oocistos. Devido à magnitude sem precedentes do surto ocorrido em Milwaukee, em abril de 1993, houve ampla divulgação e muitos estudos se iniciaram. Informações coletadas durante este e em outros surtos posteriores vêm sendo avaliadas, com o objetivo de se definirem medidas efetivas que possam reduzir o risco de futuros surtos de doenças veiculadas pela água (Widmer et al, 1996). No Brasil, a própria explicitação dessa preocupação na legislação (BRASIL, 2004) 
vem induzindo a avaliações mais cuidadosas sobre os riscos envolvidos.

Foi realizada uma revisão da literatura sobre a epidemiologia e as causas de 35 surtos envolvendo Cryptosporidium nos EUA, Canadá e Reino Unido. Os surtos foram associados a sistemas de águas superficiais filtradas e não filtradas e um número significativo a sistemas de águas subterrâneas. Em sua maioria, as fontes de contaminação foram identificadas e as deficiências no tratamento e operação foram documentadas, incluindo coagulação ineficiente, inadequadas operação e monitoramento do processo de filtração e traspasse na filtração. A contaminação de sistemas de distribuição também foi identificada como responsável por surtos (Craun et al, 1998).

Nos surtos associados a águas subterrâneas, foi observado que poços e fontes não estavam devidamente protegidos do contato com esgotos ou com escoamentos superficiais e alguns poços eram localizados em áreas adjacentes e influenciadas por rios e córregos (Craun et al, 1998).

Em todos os países estudados, nos surtos relacionados a águas superficiais, a contaminação foi devida a descargas de esgotos humanos e escoamentos de áreas de agricultura, especialmente onde esterco tinha sido aplicado ou a área estava sendo usado como área de pastagem. Estes surtos ocorreram durante períodos de chuvas fortes, que carrearam os resíduos dos animais até as fontes, ou, em época de seca, quando as fontes apresentavam uma maior concentração de esgoto (Leland et al, 1993). Uma importante causa de contaminação em um surto foi a reciclagem direta de águas de retrolavagem dos filtros, sem tratamento prévio (Richardson et al, 1991).

Pesquisas efetuadas sobre o surto ocorrido em Milwaukee avaliaram registros nos níveis de turbidez da água tratada da ETA Sul, constatando um pico anômalo oito dias antes do máximo de casos confirmados em laboratórios. Evidências circunstanciais adicionais incriminando o sistema da água vieram das análises do gelo produzido durante o tempo da água com alta turbidez, em que foi encontrada concentração de 13 oocistos/100L (Widmer et al, 1996).

Um tema chave no monitoramento dos sistemas de distribuição das águas de abastecimento é a variação nas densidades dos microrganismos. A variação é temporal - dia a dia, estação a estação - e espacial, entre as diferentes partes do sis- tema de distribuição ao mesmo tempo. A maioria das amostras de sistemas de distribuição de água potável de países desenvolvidos registra contagens iguais a zero, particularmente nos casos das bactérias do grupo coliforme e E.coli (em 100mL) e de patógenos (em 100L) (Christian \& Pipes, 1983; Gale, 1996).

Ainda não está clara a associação entre as densidades de oocistos de Cryptosporidium sp medidas nos suprimentos de águas de abastecimento e o risco de ocorrência de um surto transmitido por estas águas. Algumas vezes, ocorreram surtos quando oocistos não foram detectados nas amostras de águas (Craun et al, 1998). Ao contrário, nem sempre ocorreram surtos quando oocistos foram detectados em sistemas de águas. A relativa falta de sensibilidade dos métodos analíticos para Cryptosporidium e Giardia em água e a falta de esclarecimento sobre o risco da doença não sustentam recomendação de um nível de ação para oocistos em águas potáveis (Gale \& Stanfield, 2000).

Bastos et al (2001) destacam sobre o uso de modelos de avaliação de risco (AR) e, mais especificamente, do estabelecimento de "níveis de alerta" em alguns países, enquanto persistirem as limitaçôes analíticas de pesquisa de protozoários em amostras de água.

Programas de monitoramento baseados em amostras pontuais geralmente tendem a subestimar o risco, sobretudo quando valorizam as médias aritméticas da concentração de oocistos nas águas de abastecimento, pois a contagem mais freqüente é zero e, as raras, mas todas importantes, amostras com contagens altas, podem ser perdidas nos cálculos estatísticos. Isto poderia contribuir para se constatar a falta de uma associação clara entre as concentrações de oocistos medidas na água e o risco de surtos de criptosporidiose na população, veiculados pela água (Gale \& Stanfield, 2000).

Podem ser destacados, como causas naturais das alteraçōes nas características das águas, o clima, a topografia e a geologia do terreno, a presença de nutrientes, os incêndios e as estratificações térmicas em lagos e reservatórios. Dentre estas, é de destaque a freqüência e a intensidade das precipitaçôes. Os períodos de estiagem favorecem a estagnação da água nos lagos e reservatórios e o florescimento de algas. Adicionalmente, a ocorrência de queimadas aumenta a erosão da bacia hidrográfica. Em contrapartida, os períodos chuvosos acarretam a ressuspensão do material sedimentado no fundo de lagos e rios, favorecendo a elevação das concentraçōes de partículas e, conseqüentemente, os cistos de Giardia e oocistos de Cryptosporidium a elas associadas (Atherholt et al, 1998; Hroncich, 1999).

A influência das precipitações na disseminação das doenças de veiculaçãoo hídrica foi confirmada em pesquisa realizada por Rose et al (2000), que analisaram os registros de surtos do período de 1971 a 1994 , envolvendo 2.105 bacias hidrográficas nos EUA. Foi verificado que de 20 a $40 \%$ dos surtos registrados naquele período estavam associados a eventos de precipitações intensas. A maioria dos casos que envolveram hospitalização (80\%) foi devido a Cryptosporidium parvum e Giardia lamblia. Foram registrados 89 óbitos, sendo que $79 \%$ ocorreram durante surtos de criptosporidiose.

O efeito das chuvas nas concentrações dos parasitas foi documentado por Stewart et al (1997) quando encontraram concentraçōes muito altas de Giardia e Cryptosporidium numa amostragem logo após uma tempestade. Eles alertaram sobre a necessidade de se fazerem amostragens durantes as chuvas fortes.

Atherholt et al (1998) também estudaram a prevalência de cistos de Giardia e oocistos de Cryptosporidium em águas superficiais. Os períodos chuvosos aumentaram as concentrações destes protozoários na água bruta, primariamente afetando a turbidez. As concentrações de bactérias do grupo coliformes, Escherichia coli, enterococos e enterovírus também foram aumentadas. Encontraram ainda que apenas 1,9\% dos cistos de Giardia observados tinham mais do que uma estrutura interna e $25 \%$ dos oocistos de Cryptosporidium detectados continham um ou mais esporozoítos, ambos indicativos de viabilidade potencial.

Apesar das limitaçōes das avaliaçōes de viabilidade de cistos e oocistos nesses estudos, deve ser enfatizado que a maioria dos surtos de criptosporidiose veiculados pela água, incluindo o surto de 1993 em Milwaukee, ocorreu durante ou após chuvas fortes e com aumento de turbidez induzido pelos escoamentos ocorridos (Morris et al, 1996).

Com o objetivo de verificar o comportamento da filtração lenta em areia, caso ocorresse um aumento súbito na concentração de oocistos de Cryptosporidium e na turbidez da água sintética, a presente pesquisa investiga uma simulação de condiçôes transientes, que poderiam ser identificadas antes do surgimento de um 
surto de criptosporidiose, com características semelhantes à ocorrência de uma chuva forte, e avalia suas conseqüências no tratamento dessas águas.

\section{MATERIAL E MÉTODOS}

\section{Aparato experimental}

Foram utilizadas duas unidades piloto de filtros lentos em areia, uma com sentido de escoamento descendente e a outra com escoamento ascendente, operadas com taxa de filtração igual a $6 \mathrm{~m}^{3} / \mathrm{m}^{2}$.dia, conforme ilustrado na Figura 1.

Cada filtro era constituído de dois tubos flangeados de acrílico superpostos, de 0,20 m de diâmetro e 1,50 m de altura. Na parte inferior de cada filtro foi fixada uma placa perfurada para sustentação dos leitos granulares, localizada a $0,10 \mathrm{~m}$ da base.

No filtro lento descendente, a entrada de água localizava-se a $0,30 \mathrm{~m}$ abaixo da borda superior do filtro $(1,45 \mathrm{~m}$ acima do leito filtrante) e a saída logo abaixo da placa perfurada, com a forma de "U" invertido, visando manter um nível mínimo de água sobre o leito de $0,45 \mathrm{~m}$. Já no filtro lento ascendente, a entrada dava-se $0,10 \mathrm{~cm}$ acima da base inferior do filtro e a saída a $0,30 \mathrm{~cm}$ abaixo da borda superior $(1,45 \mathrm{~m}$ acima do leito filtrante).

O leito filtrante de ambos os filtros foi constituído por areia, com espessura de $0,75 \mathrm{~m}$, tamanho efetivo de $0,25 \mathrm{~mm}$, coeficiente de uniformidade de 2,40, diâmetro mínimo de 0,084 mm e diâmetro máximo de $1,00 \mathrm{~mm}$. A camada suporte constituiu-se de três camadas de seixos rolados, de granulometria variando entre 1,20 e $19,10 \mathrm{~mm}$.
A unidade ascendente já estava 30 dias em operação, período que foi considerado neste estudo como fase estacionária do filtro. A unidade descendente foi colocada em operação para que quando completasse $12 \mathrm{~h}$ de carreira fosse feita a simulação do pico.

\section{Água sintética}

Para o preparo da água sintética, foi captada água da rede pública, que foi posteriormente desclorada por filtros de carvão ativado e nela acrescentados:

- bentonita, para geração de turbidez;

- efusão de erva mate, para produção de cor verdadeira; de $\mathrm{pH}$;

- ácido sulfúrico $1 \mathrm{~N}$ para correção

- alíquota de esgoto, que forneceu os microrganismos analisados (coliformes totais, Escherichia coli, esporos de bactérias anaeróbias e Clostridium perfringens, esporos de bactérias aeróbias e Bacillus subtilis, cistos de Giardia);

- oocistos de Cryptosporidium, produzidos em um bezerro neonato.

As concentrações das substâncias, oocistos e esgotos adicionadas nas águas para caracterizar as condiçōes estacionárias e transientes estão descritas abaixo, na Tabela 1.

Inicialmente foram preparados $400 \mathrm{~L}$ da água sintética e, diariamente, 200 L eram preparados e adicionados à caixa de abastecimento de forma a deixar sempre um nível de água que permitisse uma mistura homogênea. Não houve um propósito de aumentar as concentraçôes de Giardia spp porque é conhecido que se houver remoção dos oocistos de Cryptosporidium sp os cistos de Giardia spp também serão removidos.

\section{Operação}

Os filtros piloto foram operados em paralelo. A água, ao chegar da rede pública de distribuição, era filtrada em carvão ativado para remoção do cloro seguindo até um reservatório de $500 \mathrm{~L}$ onde foram incorporadas as substâncias descritas na Tabela 1, caracterizando a água experimental. Esta foi recalcada através de bomba peristáltica de múltiplos canais até os filtros piloto, utilizando-se a taxa de filtração de $6 \mathrm{~m}^{3} / \mathrm{m}^{2}$.d. O reservatório de alimentação distribuiu o mesmo efluente para cada um dos filtros, permitindo assim uma avaliação da resposta aos diferentes sentidos dos fluxos, descendente e ascendente.

As vazōes afluentes foram verificadas diariamente, assim como as perdas de carga e o funcionamento geral do sistema. As taxas de filtração foram aferidas volumetricamente, por envolver vazóes muito pequenas e a sensibilidade dos rotâmetros não atender a esta necessidade.

\section{Planejamento de coleta e análise das amostras}

\section{A) Condição estacionária}

- Filtros Lentos Descendentes (FLD): foram realizados dois experimentos - a primeira carreira iniciou-se no dia $18 / 12 / 2000$ e terminou no dia $24 / 12 / 2000$ e a segunda foi de 07/02/2001 a 13/02/2001.

- Filtros Lentos Ascendentes (FLA): foram realizados dois experimentos - simultaneamente com o filtro descendente na primeira carreira, a carreira começou no dia 18/12/2000, mas somente terminou no dia 17/01/2001, após os 30 dias corridos estipulados inicialmente; e sua duplicata foi de 24/06/2001 a 30/07/2001.

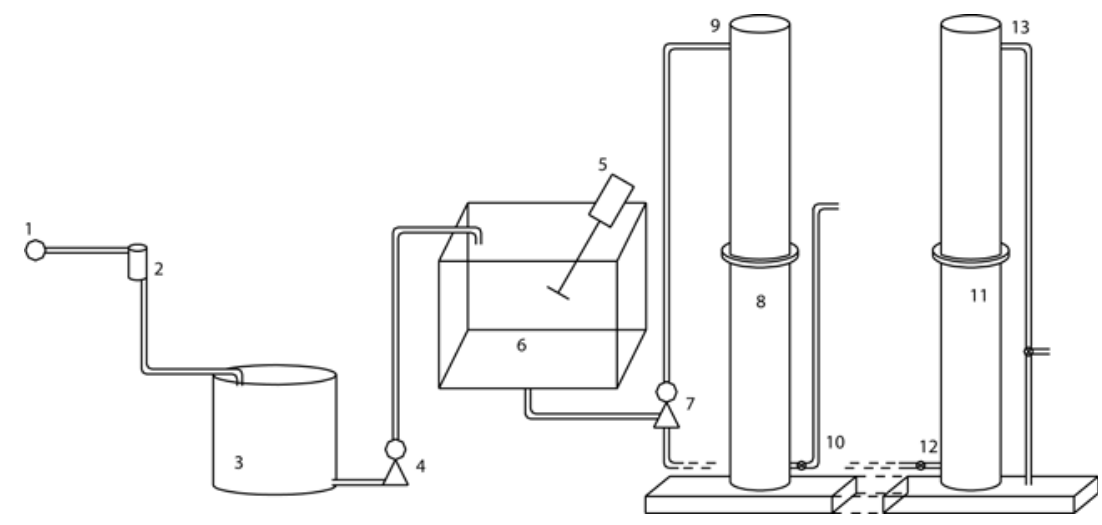

LEGENDA

1. Entrada de água da rede

2. Filtro de Carvão Ativado

3. Caixa de preparação de água bruta - $250 \mathrm{~L}$

4. Bomba centrífuga

5. Misturador

6. Caixa de armazenamento de água bruta $(500 \mathrm{~L})$

7. Bomba peristáltica para alimentação dos filtros

8. FLD

9. Entrada de água bruta no FLD

10. Saída de água filtrada do FLD

11. FLA

12. Entrada de água bruta no FLA

13. Saída de água filtrada do FLA

Figura I - Esquema da planta piloto 
Tabela I - Características gerais da água sintética

\begin{tabular}{|c|c|c|}
\hline \multirow[t]{2}{*}{ Características da água sintética } & \multicolumn{2}{|r|}{ Valores do experimento } \\
\hline & Planejados & Substâncias adicionadas (400L) \\
\hline $\begin{array}{r}\text { Turbidez }(\mathrm{uT}) \text { - condição estacionária } \\
\text { condição transiente } 1\end{array}$ & $15 \pm 5$ & $14 \mathrm{~g}$ de bentonita \\
\hline condição transiente 2 & $35 \pm 5$ & $33 \mathrm{~g}$ de bentonita \\
\hline Cor verdadeira $(\mathrm{uC})$ & $15 \pm 5$ & $160 \mathrm{~mL}$ de efusão de erva mate \\
\hline $\mathrm{pH}$ & $7,0 \pm 0,5$ & $100 \mathrm{~mL}$ de solução $\mathrm{H}_{2} \mathrm{SO}_{4} 1 \mathrm{~N}$ \\
\hline Coliformes totais - condição estacionária & $5 \times 10^{3}$ & $40 \mathrm{~mL}$ de esgoto sanitário* \\
\hline$(\mathrm{NMP} / 100 \mathrm{~mL})$ condição transiente 1 e 2 & $5 \times 10^{4}$ & $400 \mathrm{~mL}$ de esgoto sanitário \\
\hline Coliformes fecais - condição estacionária & $1 \times 10^{3}$ & $40 \mathrm{~mL}$ de esgoto sanitário \\
\hline$(\mathrm{NMP} / 100 \mathrm{~mL})$ condição transiente 1 e 2 & $1 \times 10^{4}$ & $400 \mathrm{~mL}$ de esgoto sanitário \\
\hline Cl. perfringens - condição estacionária. & - & $40 \mathrm{~mL}$ de esgoto sanitário \\
\hline$(\mathrm{NMP} / 100 \mathrm{~mL}) \quad$ condição transiente 1 e 2 & - & $400 \mathrm{~mL}$ de esgoto sanitário \\
\hline Bacillus subtilis - condição estacionária & - & $40 \mathrm{~mL}$ de esgoto sanitário \\
\hline$(\mathrm{NMP} / 100 \mathrm{~mL}) \quad$ condição transiente 1 e 2 & - & $400 \mathrm{~mL}$ de esgoto sanitário \\
\hline Giardia spp - condição estacionária & - & $40 \mathrm{~mL}$ de esgoto sanitário \\
\hline (cistos/100L) - condição transiente 1 e 2 & - & $400 \mathrm{~mL}$ de esgoto sanitário \\
\hline Cryptosporidium parvum - condição estacionária & $1 \times 10^{2}$ & $55 \mu \mathrm{L}$ de oocistos de sol. estoque** \\
\hline (oocistos/100L) condição transiente 1 e 2 & $1 \times 10^{3}$ & $550 \mu \mathrm{L}$ de oocistos de sol. estoque** \\
\hline
\end{tabular}

\section{B) Condiçóes transientes}

As condições transientes caracterizaram-se, inicialmente, por um aumento na concentração dos oocistos de Cryptosporidium parvum (condição transiente 1) e, posteriormente (após 48h), mantendo-se a concentração dos oocistos da condição 1, por um aumento na concentração de bentonita e, conseqüentemente, uma elevação na turbidez (condição transiente 2). Em resumo, foram simulados dois picos: um de oocistos e outro de oocistos mais turbidez (Figura 2).

\section{Amostragem}

As amostras das águas foram cole- tadas na água bruta e na água filtrada. Para as análises bacteriológicas foram coletados, assepticamente, $500 \mathrm{~mL}$ de amostra em frascos esterilizados e volumes de 10 L em galóes desinfetados, para as análises de protozoários.

\section{Análises físico-químicas}

Os seguintes parâmetros físico-químicos foram monitorados diariamente: cloro total, cloro livre, cor aparente, cor verdadeira, $\mathrm{pH}$ e turbidez. As análises tradicionais seguiram aquelas delineadas pela $20^{a}$ ed. do Standard Methods for the Examination of Water and Wastewater (1998) e se encontram referenciadas na Tabela 2.

\section{Análises microbiológicas}

$\mathrm{Na}$ Tabela 3 estão sumarizados os métodos microbiológicos dos parâmetros monitorados.

Os protozoários Cryptosporidium sp e Giardia spp, microrganismos aos quais foi dada maior ênfase neste estudo, foram concentrados usando-se o método da floculação com carbonato de cálcio desenvolvido por Vesey et al (1993). Para identificação dos cistos e oocistos nas amostras concentradas, foi aplicada a técnica de imunofluorescência direta, utilizandose o "kit" Merifluor ${ }^{\circledR}$ C/G (Cod. 250050).

\begin{tabular}{|c|c|c|c|c|c|c|c|}
\hline $\begin{array}{l}29 / 7 \\
\downarrow \\
\end{array}$ & $\begin{array}{c}30 / 7 \\
\downarrow\end{array}$ & $\downarrow$ & $\begin{array}{c}31 / 7 \\
\downarrow\end{array}$ & $\downarrow$ & $\begin{array}{l}1 / 8 \\
\downarrow\end{array}$ & $\downarrow$ & $\begin{array}{r}2 / 8 \\
\downarrow\end{array}$ \\
\hline $\mathrm{Oh}$ & $8 \mathrm{~h}$ & $20 \mathrm{~h}$ & $8 \mathrm{~h}$ & $20 \mathrm{~h}$ & $\begin{array}{l}8 \mathrm{~h} \\
\boldsymbol{4}\end{array}$ & $20 \mathrm{~h}$ & $8 \mathrm{~h}$ \\
\hline \multicolumn{3}{|c|}{ Pico de oocistos } & \multicolumn{5}{|c|}{ Pico de oocistos + turbidez } \\
\hline
\end{tabular}

Figura 2 - Diagrama da condução das condições transientes 
Tabela 2 - Parâmetros e métodos físico-químicos analisados

\begin{tabular}{ccc}
\hline Parâmetro & Método analítico & Equipamento \\
\hline Cloro total & Standard Methods 8187 & $\begin{array}{c}\text { EspectrofotômetroHACH } \\
\text { Mod.DR2010 }\end{array}$ \\
Cloro livre & Standard Methods 10069 & $\begin{array}{c}\text { EspectrofotômetroHACH } \\
\text { Mod.DR2010 }\end{array}$ \\
Cor aparente & Standard Methods 8025 & $\begin{array}{c}\text { EspectrofotômetroHACH } \\
\text { Mod.DR2010 }\end{array}$ \\
Cor verdadeira & Standard Methods 8025 & $\begin{array}{c}\text { EspectrofotômetroHACH } \\
\text { pH }\end{array}$ \\
Turbidez & Standard Methods 4500H A) Phâmetro ORION Mod. 210A & Mod.DR2010 \\
& Stand Methods 2130B & Turbidímetro HACH \\
& & Mod.2100AN \\
\hline
\end{tabular}

Tabela 3 - Parâmetros e métodos microbiológicos analisados

\begin{tabular}{cc}
\hline Parâmetro & Método analítico \\
\hline Coliformes totais e Escherichia coli & Colilert@ - Standard Methods 9223 \\
Esporos de bactérias anaeróbias e & Fout et al (1996) - EPA/ICR \\
Clostridium perfringens & \\
Esporos de bactérias aeróbiase & Rice et al (1994), modificado por \\
Bacillus subtilis & Nieminski et al (2000) \\
Giardia spp e Cryptosporidium sp & Vesey et al (1993) \\
\hline
\end{tabular}

\section{Análises estatísticas e recursos computacionais}

As análises estatísticas foram efetuadas através dos softwares Microsoft Excel for Windows, Kruskal (LCC - UFMG) e Statistica 5.0 (Statsoft inc.), de acordo com as especificidades de cada pacote e com as demandas do estudo.

O pacote Kruskal, com adaptações realizadas pelo Prof. Ivan Sampaio (Escola de Veterinária - UFMG) e com versão do Laboratório de Computação Científica da UFMG, foi utilizado para executar a análise não paramétrica de Kruskal Wallis dos dados físico-químicos, bacteriológicos e parasitológicos. O programa Statistica 5.0 foi utilizado em análises de estatística descritiva e para cálculo das correlações de Spearman.

\section{RESULTADOS}

\section{Turbidez}

Durante a condição transiente 2 , a mediana do pico de turbidez afluente passou da faixa de 12 a $15 \mathrm{uT}$ para $31,5 \mathrm{uT}$, atendendo ao inicialmente planejado.

A estatística descritiva dos valores da turbidez dos efluentes dos filtros nas di- lentes, independente também do sentido do fluxo.

\section{Esporos de bactérias anaeróbias}

Os resultados permitem observar que, mesmo com o nível elevado da concentração dos esporos anaeróbios nas condições transientes, com destaque para a condição transiente 1, os efluentes dos filtros não apresentaram esporos anaeróbios, em termos medianos. $\mathrm{Na}$ Tabela 5 está representada a análise estatística descritiva dos resultados dos esporos anaeróbios obtidos nos efluentes dos filtros nos diversos tratamentos.

Pela comparação da ordenação média dos resultados obtidos para esporos anaeróbios, resultante da aplicação do teste de Kruskal-Wallis (Sampaio, 1998), observou-se que os diversos tratamentos estatisticamente equivalentes.

\section{Clostridium perfringens}

Os resultados mostraram que todas as medianas dos resultados dos efluentes foram zero, a despeito do aumento das concentrações nas águas sintéticas das condiçôes transientes devido ao aumento da concentração dos esgotos adicionados.

Na Tabela 6 pode-se visualizar a análise estatística descritiva dos dados de C. perfringens obtidos nos efluentes dos filtros nos diversos tratamentos.

$\mathrm{Na}$ Tabela 7 estão os resultados do Teste de Kruskal-Wallis para os dados não paramétricos obtidos de $C$. perfringens nos efluentes dos filtros durante os experimentos das condições transientes e estasentada na Tabela 4.

Como os resultados obtidos para turbidez não apresentaram uma distribuição normal, foram tratados estatisticamente como dados não paramétricos, sendo aplicado o método de Kruskal-Wallis (Sampaio, 1998), o que pemitiu concluir que, apesar de a turbidez da água afluente ter dobrado de valor, as concentrações nos efluentes filtrados foram levemente superiores, mas estatisticamente equivacionária.

Tabela 4 - Estatística descritiva dos valores da turbidez nas diversas condições de tratamento estabelecidas nos filtros lentos descendente e ascendente

\begin{tabular}{ccccccc}
\hline & \multicolumn{2}{c}{$\begin{array}{c}\text { Condição } \\
\text { estacionária }\end{array}$} & \multicolumn{2}{c}{ Condição } & \multicolumn{2}{c}{ Condição } \\
& transiente-1 & \multicolumn{2}{c}{ transiente-2 } \\
& D & A & D & A & D & A \\
\hline N & 12 & 64 & 3 & 3 & 3 & 3 \\
Média (uT) & 0,82 & 0,87 & 1,25 & 0,92 & 1,54 & 1,17 \\
Mediana (uT) & $0,72^{\mathrm{a}}$ & $0,80^{\mathrm{a}}$ & $1,30^{\mathrm{a}}$ & $0,92^{\mathrm{a}}$ & $1,22^{\mathrm{a}}$ & $1,10^{\mathrm{a}}$ \\
Mínimo (uT) & 0,33 & 0,19 & 0,94 & 0,75 & 0,93 & 0,80 \\
Máximo (uT) & 1,74 & 3,38 & 1,50 & 1,10 & 2,48 & 1,60 \\
Desvio padrão(uT) & 0,43 & 0,61 & 0,28 & 0,18 & 0,82 & 0,40 \\
\hline
\end{tabular}

${ }^{a}$ Medianas com pelo menos uma letra em comum são equivalentes 
Houve diferença estatisticamente significativa entre a condição estacionária e a condição transiente- 2 do filtro descendente, quando houve aumento da turbidez. Isto sugere que, com o aumento da turbidez, as concentrações de C. perfringens aumentaram significativamente no efluente do filtro descendente, mas distinguindo apenas da condição estacionária. Indica maior vulnerabilidade do filtro nessa condição.

\section{Esporos de bactérias aeróbias}

Os valores medianos dos esporos das bactérias, durante a aplicação das condições transientes e estacionárias, estão apresentados na Figura 3.

Pode-se observar que, durante a condição estacionária, as concentrações dos esporos aeróbios nos efluentes dos filtros diminuíram em pequena quantidade. Ao contrário, durante a condição transiente 1 , a concentração dos esporos aeróbios aumentou no FLA, diminuindo muito pouco no FLD. Na condição transiente 2 , no FLA manteve-se igual, e no FLD observou-se comportamento semelhante.

$\mathrm{Na}$ Tabela 8 está apresentada a estatística descritiva dos dados obtidos para os esporos aeróbios durante as condições transientes.

Os resultados encontrados por meio do teste de Kruskal-Wallis estão ordenados na Tabela 9. Houve diferença significativa nas concentrações entre a condição estacionária e a transiente-1 do FLA, quando se aumentaram apenas os oocistos.

\section{Bacillus subtilis}

Na Tabela 10 está apresentada a estatística descritiva dos B. subtilis nas diversas condiçóes de tratamentos efetuados. Pode ser observado que existiram valores numéricos para as médias aritméticas das concentraçóes dos microrganismos, mas a mediana só não foi zero para o efluente do filtro A6 na condição transiente 1.

A estatística não paramétrica de Kruskal-Wallis está apresentada na Tabela 11 .

Houve diferença significativa nas concentrações de $B$. subtilis do efluente do filtro A6 quando a turbidez foi aumentada na condição transiente- 2 , mas observando que houve redução da concentração do microrganismo quando submetido à nova condição.

Tabela 5 - Estatística descritiva dos esporos de bactérias anaeróbias nas diversas condições de tratamento estabelecidas nos filtros lentos descendente e ascendente

\begin{tabular}{ccccccc}
\hline & \multicolumn{2}{c}{$\begin{array}{c}\text { Condição } \\
\text { estacionária }\end{array}$} & \multicolumn{2}{c}{ Condição } & \multicolumn{2}{c}{ Condição } \\
& $\mathrm{D}$ & $\mathrm{A}$ & $\mathrm{D}$ & $\mathrm{A}$ & $\mathrm{D}$ & $\mathrm{A}$ \\
\hline $\mathrm{N}$ & 10 & 25 & 3 & 3 & 3 & 3 \\
Média* & 4,3 & 6,3 & 0,0 & 0,0 & 0,3 & 0,0 \\
Mediana* $^{*}$ & $0,5^{\mathrm{a}}$ & $0,0^{\mathrm{a}}$ & $0,0^{\mathrm{a}}$ & $0,0^{\mathrm{a}}$ & $0,0^{\mathrm{a}}$ & $0,0^{\mathrm{a}}$ \\
Mínimo* $^{*}$ & 0,0 & 0,0 & 0,0 & 0,0 & 0,0 & 0,0 \\
Máximo* $^{*}$ & 20,0 & 81,0 & 0,0 & 0,0 & 1,0 & 0,0 \\
Desvio padrão* & 6,8 & 18,3 & 0,0 & 0,0 & 0,6 & 0,0 \\
\hline
\end{tabular}

*Unidade $(\mathrm{UFC} / 100 \mathrm{~mL})$

${ }^{a}$ Medianas com pelo menos uma letra em comum são equivalentes

Tabela 6 - Estatística descritiva dos C.perfringens nas diversas condições de tratamento estabelecidas nos filtros lentos descendente e ascendente

\begin{tabular}{|c|c|c|c|c|c|c|}
\hline & \multicolumn{2}{|c|}{$\begin{array}{l}\text { Condição } \\
\text { estacionária }\end{array}$} & \multicolumn{2}{|c|}{$\begin{array}{l}\text { Condição } \\
\text { transiente-1 }\end{array}$} & \multicolumn{2}{|c|}{$\begin{array}{l}\text { Condição } \\
\text { transiente-2 }\end{array}$} \\
\hline & $\mathrm{D}$ & A & $\mathrm{D}$ & A & $\mathrm{D}$ & A \\
\hline $\mathrm{N}$ & 10 & 25 & 3 & 3 & 3 & 3 \\
\hline Média* & 0,0 & 0,8 & 0,0 & 0,0 & 0,3 & 0,0 \\
\hline Mediana* & $0,0^{\mathrm{a}}$ & $0,0^{\mathrm{a}}$ & $0,0^{\mathrm{a}, \mathrm{b}}$ & $0,0^{\mathrm{a}}$ & $0,0^{\mathrm{b}}$ & $0,0^{\mathrm{a}, \mathrm{b}}$ \\
\hline Mínimo* & 0,0 & 0,0 & 0,0 & 0,0 & 0,0 & 0,0 \\
\hline Máximo* & 0,0 & 20,0 & 0,0 & 0,0 & 1,0 & 0,0 \\
\hline Desvio padrão & 0,0 & 4,0 & 0,0 & 0,0 & 0,6 & 0,0 \\
\hline
\end{tabular}

Tabela 7 - Ordenações médias e comparação de C. perfringens pelo teste não paramétrico de Kruskal-Wallis

\begin{tabular}{|c|c|c|c|}
\hline Filtros Lentos & Estacionária & Transiente-1 & Transiente-2 \\
\hline \multirow[t]{2}{*}{ Descendente } & $22,50^{a}$ & $=22,50^{\mathrm{a}, \mathrm{b}}$ & $30,33^{b}$ \\
\hline & $=$ & $=$ & $=$ \\
\hline Ascendente & $24,38^{\mathrm{a}}$ & $22,50^{\mathrm{a}}$ & $22,50^{\mathrm{a}, \mathrm{b}}$ \\
\hline
\end{tabular}

\section{Coliformes totais}

$\mathrm{Na}$ Figura 4 estão representados os resultados obtidos das medianas das concentrações de coliformes totais nas águas afluentes e efluentes dos filtros nas diversas condiçôes de tratamento. É interessante observar, nas condições transientes 1 e 2 , que as medianas das concentrações dos coliformes totais nos efluentes do filtro ascendente sempre foram menores do que no filtro descendente, nas duas condiçōes, provavelmente devido à influência de início de carreira.
A estatística descritiva dos dados sobre os coliformes totais está apresentada na Tabela12. Aqui também se pode observar que as médias aritméticas das concentraçōes dos coliformes totais repetem o verificado para as medianas: no filtro ascendente sempre em menores concentraçōes do que no filtro descendente, nas condições transientes.

$\mathrm{Na}$ Tabela 13 estão os resultados obtidos do teste de Kruskal-Wallis.

Constata-se que houve diferença significativa nas concentraçôes dos coliformes totais entre a condição estacio- 


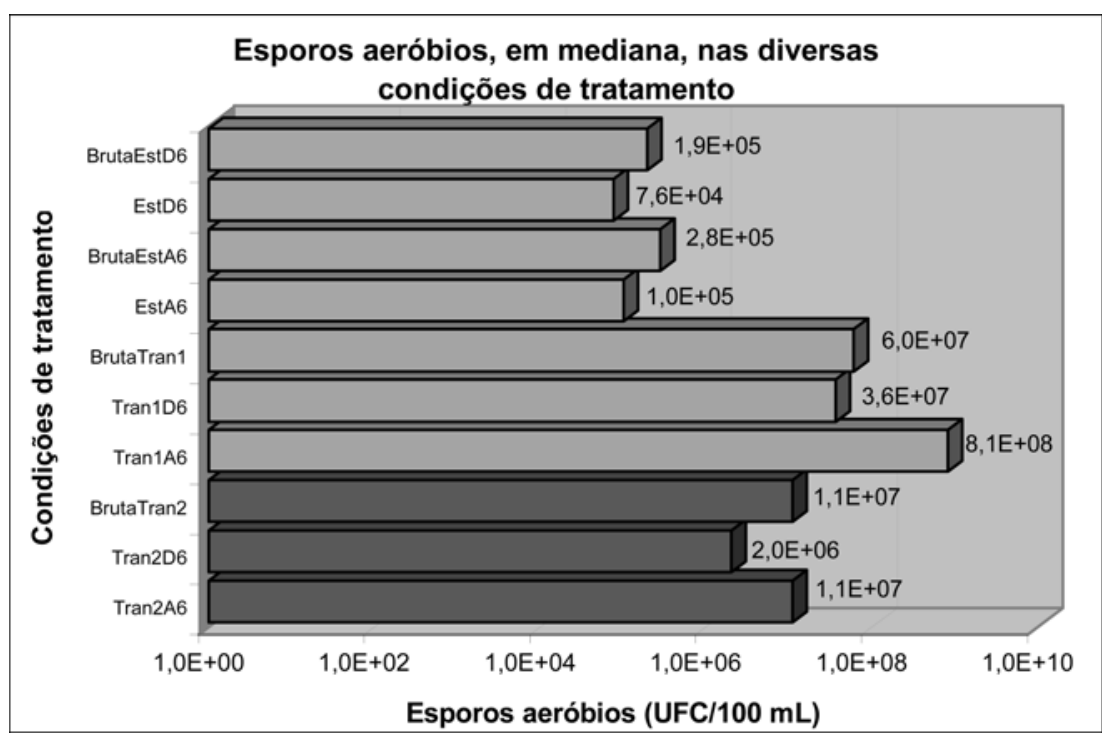

Legenda:

Bruta da Condição Estacionária do FLD Taxa 6 - BrutaEstD6

Filtrada da Condição Estacionária do FLD Taxa 6 - EstD6

Bruta da Condição Estacionária do FLA Taxa 6 - BrutaEstA6

Filtrada da Condição Estacionária do FLA Taxa 6 - EstA6

Bruta da Condição Transiente 1 BrutaTran 1

Filtrada da Condição Transiente 1 do FLD Taxa 6 - Tran1D6

Filtrada da Condição Transiente 1 do FLA Taxa 6 - Tran1A6

Bruta da Condição Transiente 2 -

BrutaTran2

Filtrada da Condição Transiente 2 do FLD Taxa 6 - Tran2D6

Filtrada da Condição Transiente 2 do FLA Taxa 6 - Tran2A6

Figura 3 - Esporos de bactérias aeróbias, em mediana, nas diversas condições de tratamento

Tabela 8 - Estatística descritiva dos esporos de bactérias aeróbias nas diversas condições de tratamento estabelecidas nos filtros lentos descendente e ascendente

\begin{tabular}{ccccccc}
\hline & \multicolumn{2}{c}{ Condição estacionária } & \multicolumn{2}{c}{ Condição transiente-1 } & \multicolumn{2}{c}{ Condição transiente-2 } \\
& $\mathrm{D}$ & $\mathrm{A}$ & $\mathrm{D}$ & $\mathrm{A}$ & $\mathrm{D}$ & $\mathrm{A}$ \\
\hline $\mathrm{N}$ & 10 & 25 & 3 & 3 & 3 & 3 \\
Média* & $2,2 \mathrm{E}+05$ & $3,8 \mathrm{E}+05$ & $3,1 \mathrm{E}+07$ & $1,2 \mathrm{E}+09$ & $9,3 \mathrm{E}+06$ & $1,3 \mathrm{E}+08$ \\
Mediana* $^{*}$ & $7,6 \mathrm{E}+04^{\mathrm{a}}$ & $1,0 \mathrm{E}+05^{\mathrm{a}}$ & $3,6 \mathrm{E}+07^{\mathrm{a}, \mathrm{b}}$ & $8,1 \mathrm{E}+08^{\mathrm{b}}$ & $2,0 \mathrm{E}+06^{\mathrm{b}}$ & $1,1 \mathrm{E}+07^{\mathrm{a}, \mathrm{b}}$ \\
Mínimo* & $1,5 \mathrm{E}+04$ & $1,0 \mathrm{E}+04$ & $1,9 \mathrm{E}+07$ & $8,1 \mathrm{E}+08$ & $0,0 \mathrm{E}+00$ & $1,0 \mathrm{E}+05$ \\
Máximo* & $8,4 \mathrm{E}+05$ & $1,2 \mathrm{E}+06$ & $3,9 \mathrm{E}+07$ & $2,1 \mathrm{E}+09$ & $2,6 \mathrm{E}+07$ & $3,7 \mathrm{E}+08$ \\
Desvio padrão* $^{*}$ & $3,2 \mathrm{E}+05$ & $4,0 \mathrm{E}+05$ & $1,1 \mathrm{E}+07$ & $7,4 \mathrm{E}+08$ & $1,4 \mathrm{E}+07$ & $2,1 \mathrm{E}+08$ \\
\hline
\end{tabular}

*Unidade (UFC/100mL)

${ }^{\mathrm{a}, \mathrm{b}}$ Medianas com pelo menos uma letra em comum são equivalentes

Tabela 9 - Ordenações médias e comparação dos esporos aeróbios pelo teste não paramétrico de Kruskal-Wallis

\begin{tabular}{|c|c|c|c|}
\hline Filtros Lentos & Estacionária & Transiente-1 & Transiente-2 \\
\hline \multirow[t]{2}{*}{ Descendente } & $20,90^{\mathrm{a}}$ & $=35,00^{\mathrm{a}, \mathrm{b}}$ & $=15,67^{\mathrm{b}}$ \\
\hline & $=$ & $=$ & $=$ \\
\hline Ascendente & $22,06^{\mathrm{a}}$ & $46,00^{\mathrm{b}}$ & $25,83^{\mathrm{a}, \mathrm{b}}$ \\
\hline
\end{tabular}


Tabela 10 - Estatística descritiva dos B.subtilis nas diversas condições de tratamento estabelecidas nos filtros lentos descendente e ascendente

\begin{tabular}{ccccccc}
\hline & \multicolumn{2}{c}{ Condição estacionária } & \multicolumn{2}{c}{$\begin{array}{c}\text { Condição } \\
\text { transiente-1 }\end{array}$} & \multicolumn{2}{c}{$\begin{array}{c}\text { Condição } \\
\text { transiente-2 }\end{array}$} \\
& $\mathrm{D}$ & $\mathrm{A}$ & $\mathrm{D}$ & $\mathrm{A}$ & $\mathrm{D}$ & $\mathrm{A}$ \\
\hline $\mathrm{N}$ & 10 & 25 & 3 & 3 & 3 & 3 \\
Média* & $2,0 \mathrm{E}+03$ & $1,1 \mathrm{E}+04$ & $1,7 \mathrm{E}+05$ & $2,7 \mathrm{E}+07$ & $6,7 \mathrm{E}+05$ & $0,0 \mathrm{E}+00$ \\
Mediana* $^{*}$ & $0,0 \mathrm{E}+00^{\mathrm{a}}$ & $0,0 \mathrm{E}+00^{\mathrm{a}, \mathrm{b}}$ & $0,0 \mathrm{E}+00^{\mathrm{a}, \mathrm{b}}$ & $5,0 \mathrm{E}+05^{\mathrm{b}}$ & $0,0 \mathrm{E}+00^{\mathrm{a}, \mathrm{b}}$ & $0,0 \mathrm{E}+00^{\mathrm{a}}$ \\
Mínimo* & $0,0 \mathrm{E}+00$ & $0,0 \mathrm{E}+00$ & $0,0 \mathrm{E}+00$ & $0,0 \mathrm{E}+00$ & $0,0 \mathrm{E}+00$ & $0,0 \mathrm{E}+00$ \\
Máximo* $^{*}$ & $1,0 \mathrm{E}+04$ & $8,0 \mathrm{E}+04$ & $5,0 \mathrm{E}+05$ & $8,0 \mathrm{E}+07$ & $2,0 \mathrm{E}+06$ & $0,0 \mathrm{E}+00$ \\
Desvio padrão* & $4,2 \mathrm{E}+03$ & $2,3 \mathrm{E}+04$ & $2,9 \mathrm{E}+05$ & $4,6 \mathrm{E}+07$ & $1,2 \mathrm{E}+06$ & $0,0 \mathrm{E}+00$ \\
\hline
\end{tabular}

*Unidade $(\mathrm{UFC} / 100 \mathrm{~mL})$

${ }^{a, b}$ Medianas com pelo menos uma letra em comum são equivalentes

Tabela I I - Ordenações médias e comparação de B.subtilis pelo teste não paramétrico de Kruskal-Wallis

\begin{tabular}{cccc}
\hline Filtros Lentos & Estacionária & Transiente-1 & Transiente-2 \\
\hline Descendente & $22,50^{\mathrm{a}}$ & $=25,83^{\mathrm{a}, \mathrm{b}}$ & $=26,33^{\mathrm{a}, \mathrm{b}}$ \\
& $=$ & $=$ & $=$ \\
Ascendente & $24,36^{\mathrm{a}}$ & $=36,00^{\mathrm{b}}$ & $\neq 16,50^{\mathrm{a}}$ \\
\hline
\end{tabular}

a,b Ordenações médias com pelo menos uma letra em comum são equivalentes

Tabela 12 - Estatística descritiva dos coliformes totais nas diversas condições de tratamento estabelecidas nos filtros lentos descendente e ascendente

\begin{tabular}{ccccccc}
\hline & \multicolumn{2}{c}{ Condição estacionária } & \multicolumn{2}{c}{$\begin{array}{c}\text { Condição } \\
\text { transiente-1 }\end{array}$} & \multicolumn{2}{c}{$\begin{array}{c}\text { Condição } \\
\text { transiente-2 }\end{array}$} \\
& $\mathrm{D}$ & $\mathrm{A}$ & $\mathrm{D}$ & $\mathrm{A}$ & $\mathrm{D}$ & $\mathrm{A}$ \\
\hline $\mathrm{N}$ & 10 & 25 & 3 & 3 & 3 & 3 \\
Média* & 86,4 & 140,5 & 1101,0 & 26,9 & 130,6 & 18,8 \\
Mediana* $^{*}$ & $12,3^{\mathrm{a}}$ & $12,2^{\mathrm{a}}$ & $1200,0^{\mathrm{b}}$ & $27,8^{\mathrm{a}, \mathrm{b}}$ & $99,0^{\mathrm{a}, \mathrm{b}}$ & $20,1^{\mathrm{a}, \mathrm{b}}$ \\
Mínimo* & 0,0 & 0,0 & 550,0 & 11,0 & 52,8 & 14,6 \\
Máximo* $^{*}$ & 390,0 & 2400,0 & 1553,0 & 41,9 & 240,0 & 21,6 \\
Desvio padrão* & 136,1 & 476,8 & 508,8 & 15,5 & 97,5 & 3,7 \\
\hline
\end{tabular}

* Unidade $(\mathrm{NMP} / 100 \mathrm{~mL})$

${ }^{a, b}$ Medianas com pelo menos uma letra em comuns são equivalentes 


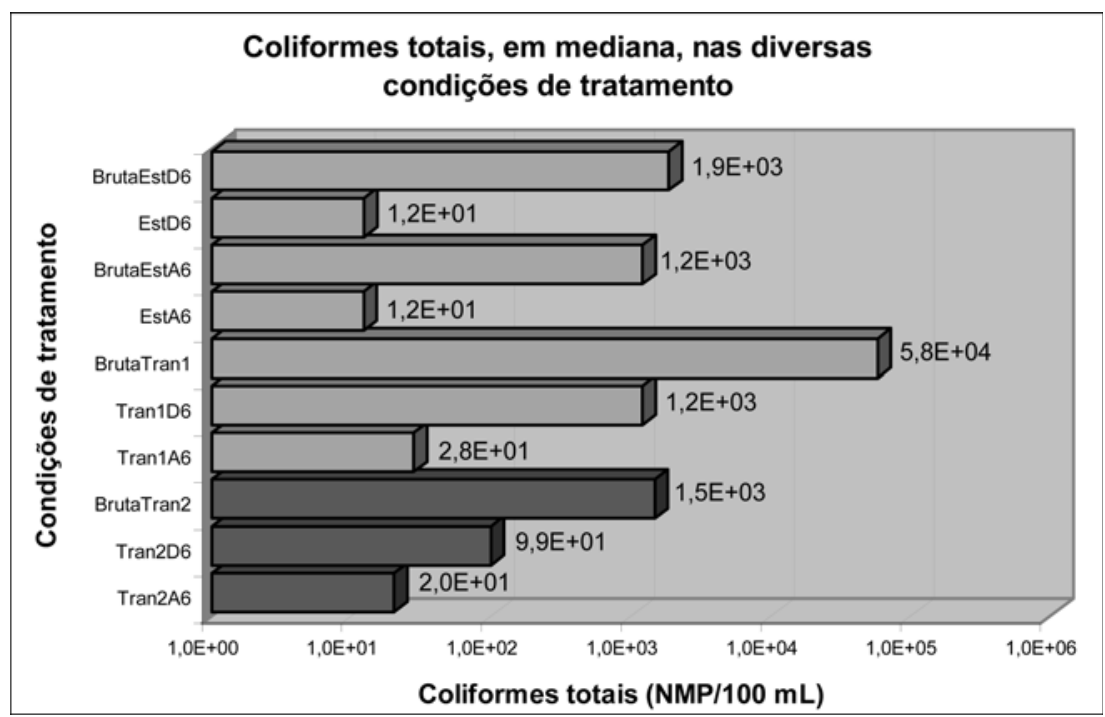

Legenda:

Bruta da Condição Estacionária do

FLD Taxa 6 - BrutaEstD6

Filtrada da Condição Estacionária do FLD Taxa 6 - EstD6

Bruta da Condição Estacionária do FLA Taxa 6 - BrutaEstA6

Filtrada da Condição Estacionária do FLA Taxa 6 - EstA6

Bruta da Condição Transiente 1 BrutaTran 1

Filtrada da Condição Transiente 1 do FLD Taxa 6 - Tran1D6 Filtrada da Condição Transiente 1 do FLA Taxa 6 - Tran1A6

Bruta da Condição Transiente 2 BrutaTran2

Filtrada da Condição Transiente 2 do FLD Taxa 6 - Tran2D6 Filtrada da Condição Transiente 2 do FLA Taxa 6 - Tran2A6

Figura 4 - Coliformes totais, em mediana, nas diversas condições de tratamento

nária e a condição transiente- 1 no filtro D6, quando apenas os oocistos foram aumentados.

\section{Escherichia coli}

Os perfis das concentraçôes de E.coli nos efluentes são semelhantes aos observados para os coliformes totais: as concentrações são bem menores nos efluentes do filtro ascendente do que no descendente, em todas as condições. Foi encontrado valor mediano zero para a concentração de E.coli na água bruta da condição transiente 2 , o que encontra respaldo em Pipes et al (1977) e Christian e Pipes (1983), em sua advertência sobre a heterogeneidade espacial nas contagens de coliformes. Mesmo usando volumes de $10 \mathrm{~L}$ para amostragem, pode haver uma subestimativa da carga microbiana. Outra possibilidade também cogitada é ocorrência de erro técnico de análise.

$\mathrm{Na}$ Tabela 14 estão os dados da estatística descritiva de E.coli, nas diversas condições de tratamento. Aqui também se confirma, observando as médias das concentrações obtidas para o filtro ascendente, nas condiçóes transientes, o assinalado para os coliformes: valores bem menores para este tipo de filtro.

$\mathrm{Na}$ Tabela 15 estão os resultados obtidos do teste de Kruskal-Wallis.

Verifica-se que houve diferença significativa entre a condição estacionária e a condição transiente-1 no FLD, quando se aumentaram apenas os oocistos, repetindo-se o ocorrido para os coliformes totais.
Tabela 13 - Ordenações médias e comparação dos coliformes totais pelo teste não-paramétrico de Kruskal-Wallis

\begin{tabular}{cccc}
\hline Filtros Lentos & Estacionária & Transiente-1 & Transiente-2 \\
\hline Descendente & $20,75^{\mathrm{a}}$ & $\neq 45,00^{\mathrm{b}}=$ & $=35,67^{\mathrm{a}, \mathrm{b}}$ \\
$=$ & $=$ & $=$ \\
Ascendente & $21,02^{\mathrm{a}}=26,17^{\mathrm{a}, \mathrm{b}}=24,83^{\mathrm{a}, \mathrm{b}}$ \\
$\begin{array}{l}\mathrm{a}, \mathrm{b} \\
\text { Ordenaçóes médias com pelo menos uma letra em comum são }\end{array}$ \\
equivalentes
\end{tabular}

Tabela 14 - Estatística descritiva de E.colinas diversas condições de tratamento estabelecidas nos filtros lentos descendente e ascendente

\begin{tabular}{ccccccc}
\hline & \multicolumn{2}{c}{$\begin{array}{c}\text { Condição } \\
\text { estacionária }\end{array}$} & \multicolumn{2}{c}{$\begin{array}{c}\text { Condição } \\
\text { transiente-1 }\end{array}$} & \multicolumn{2}{c}{$\begin{array}{c}\text { Condição } \\
\text { transiente-2 }\end{array}$} \\
& $\mathrm{D}$ & $\mathrm{A}$ & $\mathrm{D}$ & $\mathrm{A}$ & $\mathrm{D}$ & $\mathrm{A}$ \\
\hline $\mathrm{N}$ & 10 & 25 & 3 & 3 & 3 & 3 \\
Média* $^{2}$ & 14,9 & 14,1 & 96,6 & 4,9 & 9,0 & 1,3 \\
Mediana* & $1,0^{\mathrm{a}}$ & $0,0^{\mathrm{a}}$ & $63,8^{\mathrm{b}}$ & $5,2^{\mathrm{a}, \mathrm{b}}$ & $7,4^{\mathrm{a}, \mathrm{b}}$ & $2,0^{\mathrm{a}}$ \\
Mínimo* & 0,0 & 0,0 & 53,6 & 2,0 & 5,1 & 0,0 \\
Máximo* & 62,0 & 200,0 & 172,5 & 7,4 & 14,5 & 2,0 \\
Desvio padrão* & 23,7 & 40,6 & 65,9 & 2,7 & 4,9 & 1,2 \\
\hline
\end{tabular}

* Unidade (NMP/100mL)

a Medianas com pelo menos uma letra em comum são equivalentes

Tabela 15 -Ordenações médias e comparação de E.coli pelo teste não paramétrico de Kruskal-Wallis

\begin{tabular}{ccccc}
\hline Filtros Lentos & Estacionária & Transiente-1 & Transiente-2 \\
\hline Descendente & $22,80^{\mathrm{a}}$ & $\neq 44,67^{\mathrm{b}}$ & $=33,67^{\mathrm{a}, \mathrm{b}}$ \\
& $=$ & $=$ & $=$ \\
Ascendente & $20,44^{\mathrm{a}}$ & $=30,67^{\mathrm{a}, \mathrm{b}}$ & $=20,67^{\mathrm{a}}$ \\
\hline
\end{tabular}

a,b Ordenações médias com pelo menos uma letra em comum são equivalentes 


\section{Cryptosporidium sp}

$\mathrm{Na}$ Figura 5 estão apresentados os dados medianos para Cryptosporidium sp, no afluente e efluente dos filtros quando operados sob as condições transientes e estacionária. Verifica-se que, de efluentes com concentraçôes medianas iguais a zero na condição estacionária, com o aumento das concentrações de oocistos - condição transiente 1 - e depois, aumento da turbidez e oocistos - condição transiente 2 - os efluentes dos filtros já apresentaram concentraçôes de oocistos, principalmente nos efluentes do filtro descendente.

$\mathrm{Na}$ Tabela 16 estão apresentados os dados obtidos do protozoário Cryptosporidium sob forma de estatística descritiva.

Os resultados do teste de KruskalWallis a que foram submetidos os dados para os oocistos de Cryptosporidium revelaram que, apesar da impressão transmitida pelo gráfico da Figura 5, de que o filtro ascendente possa ter uma melhor eficiência em termos de remoção dos oocistos, não se verifica diferença significativa nas concentraçôes de oocistos, nos efluentes dos filtros, nas diversas condições de tratamento. Talvez o pequeno número de amostras analisado nas condições transientes possa estar influenciando os resultados, mas o número de amostras é o mesmo para os dois filtros, nas duas condiçōes.

\section{Giardia spp}

Todos os efluentes apresentaram medianas zero, independente da condição aplicada.

Na Tabela 17 está apresentada a estatística descritiva dos resultados obtidos na pesquisa dos cistos de Giardia spp nos diversos tratamentos impostos nos filtros. Pode ser salientado que apenas na condição estacionária foram observados valores maiores que zero.

A comparação da ordenação média dos dados obtidos para os cistos de Giardia spp, aplicando-se o método de Kruskal-Wallis, mostrou que todos os efluentes foram equivalentes estatisticamente.

\section{DISCUSSÃO}

Apesar das condições transientes, foi observada remoção percentual média, muito elevada dos oocistos de Cryptosporidium sp (99,988-99,998\%) e integral dos cistos de Giardia spp, independente do sentido do fluxo dos filtros lentos. Os esporos de bactérias anaeróbias e Clostridium perfringens foram os parâmetros que apresentaram os percentuais de remoções mais semelhantes aos dos protozoários. Os coliformes totais, a turbidez e a E.coli apresentaram percentuais um pouco menores e similares. Os esporos de bactérias aeróbias juntamente com os B.subtilis não foram re- movidos no FLA. Talvez possa ter havido crescimento dentro dos leitos filtrantes; excetuando o caso do FLD que removeu 93,750\% dos B. subtilis.

Bellamy et al (1985), em estudo pioneiro sobre a remoção de cistos de Giardia lamblia em filtros lentos de areia, observaram, para todas as condiçóes de operaçōes testadas, que a remoção dos cistos excedeu a $98 \%$. Uma vez que a população microbiológica dentro do leito filtrante está estabelecida, a remoção foi virtualmente de $100 \%$. O percentual de remoção é influenciado muito mais fortemente pela maturidade microbiológica do leito filtrante de areia do que pelas concentraçôes de cistos no afluente, segundo os autores.

Fogel et al (1993), estudando a remoção de Cryptosporidium e Giardia usando processo de filtração lenta em areia, também encontraram que mudanças nos níveis de turbidez nos afluentes não tiveram nenhum efeito perceptível na remoção de cistos ou oocistos. A carga afluente de coliformes totais e fecais também não influenciou sobre a remoção dos protozoários. Concluíram que os filtros lentos de areia, quando propriamente projetados, construídos, operados e mantidos, podem ser efetivos na remoção de cistos de Giardia de uma fonte de água com uma contaminação acima da faixa considerada dentro das condiçôes de operação. A explicação encontrada sobre o por quê dos oocistos de Cryptosporidium

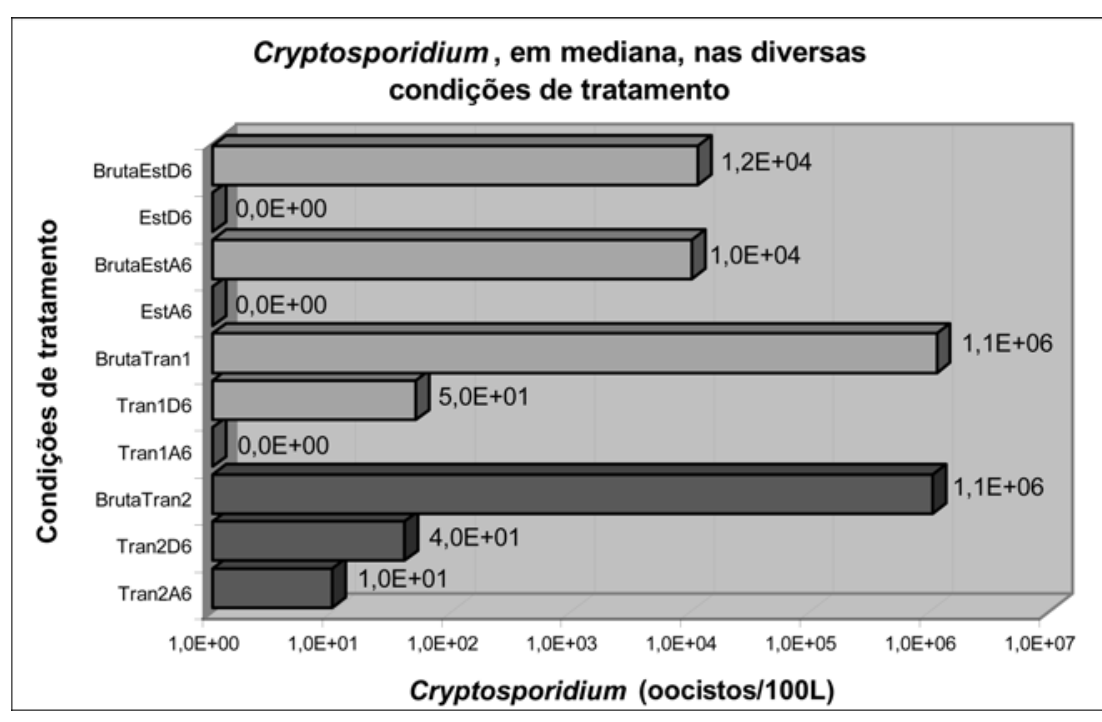

Legenda:

Bruta da Condição Estacionária do FLD Taxa 6 - BrutaEstD6

Filtrada da Condição Estacionária do FLD Taxa 6 - EstD6

Bruta da Condição Estacionária do FLA Taxa 6 - BrutaEstA6

Filtrada da Condição Estacionária do FLA Taxa 6 - EstA6

Bruta da Condição Transiente 1 BrutaTran 1

Filtrada da Condição Transiente 1 do FLD Taxa 6 - Tran1D6

Filtrada da Condição Transiente 1 do FLA Taxa 6 - Tran1A6

Bruta da Condição Transiente 2 BrutaTran2

Filtrada da Condição Transiente 2 do FLD Taxa 6 - Tran2D6

Filtrada da Condição Transiente 2 do FLA Taxa 6 - Tran2A6

Figura 5 - Cryptosporidium sp, em mediana, nas diversas condições de tratamento 
Tabela 16 - Estatística descritiva do Cryptosporidium sp nas diversas condições de tratamento estabelecidas nos filtros lentos descendente e ascendente

\begin{tabular}{ccccccc}
\hline & \multicolumn{2}{c}{ Condição estacionária } & \multicolumn{2}{c}{$\begin{array}{c}\text { Condição } \\
\text { transiente-1 }\end{array}$} & \multicolumn{2}{c}{$\begin{array}{c}\text { Condição } \\
\text { transiente-2 }\end{array}$} \\
& $\mathrm{D}$ & $\mathrm{A}$ & $\mathrm{D}$ & $\mathrm{A}$ & $\mathrm{D}$ & $\mathrm{A}$ \\
\hline $\mathrm{N}$ & 10 & 25 & 3 & 3 & 3 & 3 \\
Média* $^{*}$ & 128,0 & 166,1 & 227,0 & 25,0 & 38,3 & 13,3 \\
Mediana* $^{*}$ & $0,0^{\mathrm{a}}$ & $0,0^{\mathrm{a}}$ & $50,0^{\mathrm{a}}$ & $0,0^{\mathrm{a}}$ & $40,0^{\mathrm{a}}$ & $10,0^{\mathrm{a}}$ \\
Mínimo* & 0,0 & 0,0 & 30,0 & 0,0 & 0,0 & 0,0 \\
Máximo* $^{*}$ & 670,0 & 1000,0 & 600,0 & 75,0 & 75,0 & 30,0 \\
Desvio padrão* & 217,3 & 297,2 & 323,0 & 43,3 & 37,5 & 15,3 \\
\hline
\end{tabular}

* Unidade (oocistos/100L)

${ }^{a}$ Medianas com pelo menos uma letra em comum são equivalentes

Tabela 17 - Estatística descritiva de Giardia spp nas diversas condições de tratamento estabelecidas nos filtros lentos descendente e ascendente

\begin{tabular}{|c|c|c|c|c|c|c|}
\hline & \multicolumn{2}{|c|}{ Condição estacionária } & \multicolumn{2}{|c|}{$\begin{array}{c}\text { Condição } \\
\text { transiente-1 }\end{array}$} & \multicolumn{2}{|c|}{$\begin{array}{c}\text { Condição } \\
\text { transiente-2 }\end{array}$} \\
\hline & $\mathrm{D}$ & A & $\mathrm{D}$ & A & $\mathrm{D}$ & A \\
\hline $\mathrm{N}$ & 10 & 25 & 3 & 3 & 3 & 3 \\
\hline Média* & 75,0 & 178,0 & 0,0 & 0,0 & 0,0 & 0,0 \\
\hline Mediana* & $0,0^{\mathrm{a}}$ & $0,0^{\mathrm{a}}$ & $0,0^{\mathrm{a}}$ & $0,0^{\mathrm{a}}$ & $0,0^{\mathrm{a}}$ & $0,0^{\mathrm{a}}$ \\
\hline Mínimo* & 0,0 & 0,0 & 0,0 & 0,0 & 0,0 & 0,0 \\
\hline Máximo* & 500,0 & 2000,0 & 0,0 & 0,0 & 0,0 & 0,0 \\
\hline Desvio padrão* & 168,7 & 464,1 & 0,0 & 0,0 & 0,0 & 0,0 \\
\hline
\end{tabular}

não terem sido efetivamente removidos foi devido à redução da atividade biológica dentro do leito filtrante, causada pelas condições de operação no frio, combinada com a uniformidade da areia, não encontrada normalmente nos projetos padronizados.

Murtha e Heller (2003), analisando a influência de fatores como taxas de filtração, sentido de fluxo, profundidade do leito filtrante e características da água bruta na eficiência de filtros lentos de areia, em escala piloto, também encontraram que o filtro de fluxo ascendente demonstrou uma ótima capacidade de amortecimento de picos de turbidez, funcionando ininterruptamente por mais de três meses, sem perda de carga e deterioração da qualidade do efluente significativas.

Atherholt et al (1998) estudaram a variabilidade das concentrações de protozoários patogênicos e de indicadores da qualidade da água no rio Delaware $-\mathrm{NJ}$ - por mais de um ano. $\mathrm{O}$ estudo mostrou que o aumento nos níveis dos protozoários foi associado com os eventos de chuvas fortes, que aumentavam a turbidez no rio. Isto foi atribuído à ressuspensão dos sedimentos ou suspensão de solos e matéria fecal antiga, mas os autores assinalaram que as descargas de esgotos são também possíveis fontes. Durante este período de amostragem intensiva, foram detectados níveis de picos de cistos e oocistos, e em muitos casos, o pico foi notado somente em um único dia, com os níveis retornando aos níveis de base no dia seguinte. Foram encontradas correlaçõoes entre concentraçôes de parasitas e coliformes totais e termotolerantes, e colifagos.

Craun et al (1998) levantaram um questionamento sobre se o monitoramento pode ou não prevenir surtos de criptosporidiose. Foram examinadas situações em que não foram encontrados oocistos durante os surtos e em que foram reportados níveis de oocistos que poderiam contribuir para um surto, baseado no modelo de Haas e Rose (1995), sem que houvesse um aumento nas doenças diarréicas. Os autores concluíram que "existem poucas evidências para uma associação entre o risco de surtos de criptosporidiose veiculados pela água e as concentraçóes de oocistos detectadas nas águas de abastecimento, com os métodos analíticos atuais". Dados publicados por LeChevalier e Norton (1995), Lisle e Rose (1995), McTigue et al (1998) e Bastos et al (2004) mostram que a presença de cistos de Giardia e oocistos de Cryptosporidium em águas tratadas não é rara.

Fogel et al (1993) detectaram oocistos nos efluentes de filtros lentos, mas não na água bruta afluente. Sugeriram dois fatores para explicar o ocorrido. Um, seria a relativa falta de precisão de amostras de pequenos volumes, gerando resultados falso negativos. O segundo, seria a habilidade observada dos leitos filtrantes de fluxo lento em deter organismos e, após um tempo, liberá-los de maneira não uniforme. 
Embora os filtros lentos de areia sejam capazes de eficiências de remoção bastante altas, controles sobre as cargas afluentes contaminadas são medidas críticas para assegurar níveis satisfatoriamente baixos de protozoários nas águas filtradas. Deste modo, um programa efetivo de gerenciamento da bacia hidrográfica, projetado especialmente para limitar a carga de protozoários contaminantes da água bruta, poderia ser uma adição útil para as ETAs serem operadas com sucesso.

Com o atual nível de informação disponível, os dados sobre a eficiência das estações de filtração lenta na remoção de oocistos de Cryptosporidium, sobretudo em situações de cargas de pico e considerando o impacto potencial deste microrganismo na saúde pública e a sua ocorrência nos mananciais, um número adicional de pesquisas na área conduziria a uma maior segurança.

\section{CONCLUSÕES}

- Apesar das condições transientes, foi observada remoção percentual média, bastante elevada para os oocistos de Cryptosporidium sp (99,988-99,998\%) e integral para os cistos de Giardia spp.

- O filtro ascendente apresentou índices de remoção levemente superiores aos do filtro descendente.

- Os esporos de bactérias anaeróbias e Clostridium perfringens foram os parâmetros que apresentaram os percentuais de remoçóes mais semelhantes aos dos protozoários. Coliformes totais, turbidez e E.coli apresentaram percentuais um pouco menores e similares.

- Os esporos de bactérias aeróbias juntamente com B.subtilis não foram removidos nos filtros lentos, excetuando o caso do filtro descendente que removeu 93,750\% de B. subtilis.

\section{AGRADECIMENTOS}

Os autores gostariam de reconhecer $\mathrm{e}$ agradecer a contribuição do Prof. Ivan B. M. Sampaio, da Escola de Veterinária da UFMG, pelo apoio no tratamento estatístico dos dados; à FAPEMIG eà FUNASA, por meio do Projeto VIGISUS, pelo apoio financeiro à pesquisa, e ao CNPq, pela concessão de bolsas.

\section{REFERÊNCIAS}

ATHERHOLT, T.B; et al. Effect of rainfall on Giardia and crypto. Journal American Water Works Association, v.90, n.9, p.66-80, 1998.
BASTOS, R.K.X.; et al. Abordagem sanitárioepidemiológica do tratamento e da qualidade parasitológica da água: entre o desejável e o possível. In: $21^{\circ}$ CONGRESSO BRASILEIRO DE ENGENHARIA SANITÁRIA E AMBIENTAL, João Pessoa, Anais Associação Brasileira de Engenharia Sanitária, 21p. 2001.

BASTOS, R. K. X., et al. Giardia sp. cysts and Cryptosporidium spp. oocysts dynamics in southeast Brazil: occurrence in surface water and removal in water treatment processes. Water Supply, v.4, n.2, p. $15-22,2004$.

BELLAMY, W.D.; et al. Removing Giardia cysts with slow sand filtration. Journal American Water Works Association, v.77, n.2, p.52-60, 1985a.

BRASIL. Ministério da Saúde. Portaria n. 518, de 25 de março de 2004. Estabelece os procedimentos e responsabilidades relativas ao controle e vigilância da qualidade da água para consumo humano e seu padrão de potabilidade, e dá outras providências. Diário Oficial da União, Brasília, v.141, n.59, p.266, Seção 1. 25 mar. 2004

CHRISTIAN, R.R.; PIPES, W.O. Frequency distribution of colifirms in water distribution systems. Applied and Environmental Microbiology, v.45, p.603, 1983.

CRAUN, G.F.; et al. Waterborne outbreaks of cryptosporidiosis. Journal American Water Works Association, v. 90, n.9, p. 81-91, 1998.

FOGEL, D.; et al. Removing Giardia and Cryptosporidium by slow sand filtration. Journal American Water Works Association, v.85, n.11, p.77-84, 1993.

FOUT, G.S.; et al. Membrane filtration method for C.perfringens. ICR Microbial Laboratory Manual, EPA 600/R -95/178, Cincinnati, 1996.

GALE, P. Coliforms in the drinking water supply: what information do the 0/100-mL samples provide? Journal Water SRT- Aqua, v.45, n.4, p.155, 1996.

GALE, P.; STANFIELD, G. Cryptosporidium during a simulated outbreak. Journal American Water Works Association, v. 92, n.9, p. 105116,2000 .

HAAS, C.N.; ROSE, J.B. Development of an action level for Cryptosporidium. Journal American Water Works Association, v.87, n.9, p.81-84, 1995 .

HRONCICH, J.A. Source water quality management. Water Quality and Treatment. 5a. Ed. USA: McGraw-Hill Inc., 1999.

LeCHEVALLIER, M.W; NORTON, W.D. Giardia and Cryptosporium in raw and finished water. Journal American Water Works Association, v.87, n.9, p.54-68, 1995.

LELAND, D.; et al. Cryptosporidiosis outbreak in a filtered water supply. Journal American Water Works Association, v.85, p.34 - 42, 1993.

LISLE, J.T., ROSE, J.B. Cryptosporidium contamination of water in the USA and UK: a mini-review. Journal Water SRT-Aqua, v.44, n.33, p. 103 - 107, 1995.

MCTIGUE, N.E. et al. National Assessment of particle removal by by filtration (90757). AWWARF, Denver, 1998.

MORRIS, R.D. et al. Temporal variation in drinking water turbidity and diagnosed gastroenteritis in Milwaukee. American Journal Public Health, v.86, p.237, 1996.

MURTHA, N.A., HELLER, L. Avaliação da influência de parâmetros de projeto e das características da água bruta no comportamento de filtros lentos de areia. Revista Engenharia Sanitária e Ambiental, v.8, n.4, p.267-277, 2003.

NIEMINSKI, E.C.; BELLAMY, W.D.; MOSS, L.R. Using surrogates to improve plant performance. Journal American Water Works Association, v.92, n.3, p.67-78, 2000.

PIPES, W.O. ; WARD, P; AHN, S.H. Frequency distributions for coliform bacteria in water. Journal American Water Works Association, v.69, p.664, 1977.

RICE, E.W.; et al. A microbiological surrogate for evaluating treatment efficiency. In: PROC. AWWA WQTC, San Francisco. 1994.

RICHARDSON, A.J.; FRANKENBERG, R.A.; BUCK, A.C. An outbreak of waterborne cryptosporidiosis in Swindon and Oxfordshire. Epidemiological Infectious, v.107, p.485, 1991.

ROSE, J.B.; et al. Climate and waterborne disease outbreaks. Journal American Water Works Association, v.92, n.9, p.77-87, 2000.

SAMPAIO, I.B.M. Estatística aplicada a experimentação animal. Belo Horizonte: FEPE MVZ, 221p. 1998

STEWART, M.H. et al. Monitoring program to determine pathogen occurrence in relationship to storm events and watershed conditions. Proc. AWWA WQTC, Denver, Nov. 9-12. 1997.

VESEY, G.; et al. A new method for the concentration of Cryptosporidium oocysts from water. Journal of Applied Bacteriology, v.75, p.82-86, 1993.

VIEIRA, M.B.C.M; et al. Verificação da ocorrência de cistos de Giardia, oocistos de Cryptosporidium e indicadores bacterianos nos esgotos sanitários da Bacia do Ribeirão Arrudas, Belo Horizonte-MG. In: IX SILUBESA SIMPÓSIO LUSO-BRASILEIRO DE ENGENHARIA SANITARIA E AMBIENTAL, Porto Seguro. Anais... Rio de Janeiro: ABES, 2000.

WIDMER, G.; CARRAWAY, M.; TZIPORI, S.Water-borne Cryptosporidium: a perspective from the USA. Pasasitology Today, v.12, n.7, p.286-290, 1996.

Endereço para correspondência:

Léo Heller

Universidade Federal de Minas Gerais Dep. de Engenharia Sanitária e Ambiental

Av. do Contorno, 842 - $7^{\circ}$ Andar 30/30-000 Belo Horizonte - MG Brasil

Tel.: (3I) 3238-1978

E-mail: heller@desa.ufmg.br 